Article

\title{
Impact of the Deposition Temperature on the Structural and Electrical Properties of InN Films Grown on Self-Standing Diamond Substrates by Low-Temperature ECR-MOCVD
}

\author{
Shuaijie Wang ${ }^{1,2}$, Fuwen Qin ${ }^{1, *}$, Yizhen Bai ${ }^{1}$, Dong Zhang ${ }^{2}$ and Jingdan Zhang ${ }^{2}$ \\ 1 School of Physics, Dalian University of Technology, Dalian 116024, China; \\ D11402027@mail.dlut.edu.cn (S.W.); baiyz@dlut.edu.cn (Y.B.) \\ 2 School of Renewable Energy, Shenyang Institute of Engineering, Shenyang 110136, China; \\ ambitious211@163.com (D.Z.); Zhangjd@sie.edu.cn (J.Z.) \\ * Correspondence: qfw@dlut.edu.cn
}

Received: 31 October 2020; Accepted: 2 December 2020; Published: 4 December 2020

\begin{abstract}
The progress of $\mathrm{InN}$ semiconductors is still in its infancy compared to GaN-based devices and materials. Herein, InN thin films were grown on self-standing diamond substrates using lowtemperature electron cyclotron resonance plasma-enhanced metal organic chemical vapor deposition (ECR-PEMOCVD) with inert $\mathrm{N}_{2}$ used as a nitrogen source. The thermal conductivity of diamond substrates makes the as-grown $\mathrm{InN}$ films especially attractive for various optoelectronic applications. Structural and electrical properties which depend on deposition temperature were systematically investigated by reflection high-energy electron diffraction (RHEED), X-ray diffraction (XRD), scanning electron microscopy (SEM), atomic force microscopy (AFM), and Hall effect measurement. The results indicated that the quality and properties of InN films were significantly influenced by the deposition temperature, and InN films with highly c-axis preferential orientation and surface morphology were obtained at optimized temperatures of $400^{\circ} \mathrm{C}$. Moreover, their electrical properties with deposition temperature were studied, and their tendency was correlated with the dependence on micro- structure and morphology.
\end{abstract}

Keywords: InN; self-standing diamond substrates; deposition temperature

\section{Introduction}

Due to their current and potential applications in an extensive range of electronic and optoelectronic devices, group III nitride semiconductors ( $\mathrm{AlN}, \mathrm{GaN}, \mathrm{InN}$ ) have received significant attention in the last 10 years and are considered as important technical materials [1-6]. Indium nitride ( $\mathrm{InN})$, which has a narrow band gap $(\sim 0.7 \mathrm{eV})$ and other extraordinary attributes, plays the key role in expanding the working wavelengths of group III nitride devices from the visible and ultraviolet to the near-infrared spectrum [7-10]. Moreover, the band gaps of ternary alloys, such as InGaN and InAlN, which are composed of InN, GaN and AlN, can cover the whole range of visible light. This enables the design of various colored light-emitting diodes (LEDs) and solar cells with relatively high efficiency. Furthermore, with its good bandgaps and performances, $\mathrm{InN}$ has been widely employed in applications of photoelectric devices, semiconductor devices with good properties and high-performance infrared detectors [8-14]. However, the progress of InN semiconductors is still in its infancy. Actually, quantum efficiency inside a GaN/InGaN solar cell prepared on a sapphire substrate is as high as $60 \%$ [12]. Therefore, various methods have been used to prepare $\mathrm{InN}$ thin films with high quality to achieve wide practical applications [15-23]. Moreover, the wavelength emitted by InN-based materials can 
reach $1.55 \mu \mathrm{m}$, which belongs to a communication band with a long wavelength. They can enrich optional materials of optical communication equipment and can bring new breakthroughs to the development of optical communication devices. In terms of electricity, theoretical studies prove that InN has good properties, for example, better properties of electron transport in both transient and steady-state situations and higher mobility $\left(14,000 \mathrm{~cm}^{2} / \mathrm{V} \cdot \mathrm{s}\right)$ and top rate $\left(4.3 \times 10^{7} \mathrm{~cm} / \mathrm{s}\right)$. All these features result in a unique advantage of $\mathrm{InN}$ in applications of high-frequency high-speed transistors and other electronic devices.

Although InN materials have unique photoelectric characteristics and potential applications, optimum-quality InN thin film growth is, to date, well developed than the nitrides of other third main group elements. This is mainly due to the following issues that need to be addressed. Firstly, it is difficult to prepare InN bulk materials because of the high pressure of nitrogen decomposition and low temperature of InN decomposition. Secondly, it is difficult to find substrate materials which can match the coefficient of expansion and lattice constant for film growth. Thirdly, optional substrates are hard to find with good performance of heat dissipation, due to the continuous durability and high heat dissipation required by high-power and high-frequency devices. Growth methods, such as metal organic chemical vapor deposition (MOCVD) [24,25], magnetron sputtering and plasma-enhanced molecular beam epitaxy (PE-MBE) [26-31], have already been adopted for the growth of InN films in recent years. Albeit these methods are used to grow $\operatorname{InN}$ thin films successfully on heterogeneous substrates such as $\alpha-\mathrm{Al}_{2} \mathrm{O}_{3}$, the heat dissipation of these substrates is not ideal. With regard to the application of high-frequency and high-power devices, it is still challenging to find suitable substrates.

With good thermal stability and high heat conductivity, diamond has dramatically improved the solidity of devices with high frequency and high power. In recent years, much progress has been achieved in the preparation of diamond films by CVD [32-35]. Diamond films of high quality and large area have been successfully deposited on substrates of metal or silicon. However, these deposition methods usually need a high temperature with relatively high energy consumption. Therefore, growth by low temperature of optimum-quality $\mathrm{InN}$ thin films on self-standing diamond substrates is the main issue in applications of InN-based optoelectronics and electronic devices with high power and high frequency. Electron cyclotron resonance plasma-enhanced metal organic chemical vapor deposition is an innovative technology of thin film deposition, which absorbs the advancement of MOCVD and $\mathrm{MBE}$, and this method uses microwave electron cyclotron resonance discharge to generate high-density charged and excited particles at low pressure.

As a new kind of thin film growth technology, ECR-PEMOCVD absorbs the advancement of MOCVD and MBE. A charge with high density and stimulated particles can be produced from this method by use of microwave electron cyclotron resonance discharge at low pressure. When active precursors were provided by the cavity-coupling ECR plasma source, the deposition temperature was effectively reduced and the reactivity of $\mathrm{N}_{2}$ can be significantly increased by the process of ECR [26]. The formation of InN thin films at a low temperature was achieved by this method. Charges with high density and excited particles can be generated at low pressure. Under such conditions, atmosphere is easy to complete in the chemical reaction on a substrate and then deposit as a thin film. The low decomposition temperature means that the growth temperature of the $\mathrm{InN}$ film is generally not higher than $600^{\circ} \mathrm{C}$. This is because the $\mathrm{N}$ equilibrium partial pressure in InN growth increases sharply with the increase in growth temperature. In order to inhibit the volatilization of $\mathrm{N}$ and $\mathrm{In}, \mathrm{InN}$ must grow at a low temperature. Since the lattice constant of diamond is $0.357 \mathrm{~nm}$ and the lattice constant of $\mathrm{InN}$ with a-axis is $0.3533 \mathrm{~nm}$, the mismatch of lattice between diamond (111) and $\operatorname{InN}(0002)$ is $19.2 \%$. Therefore, compared with traditional plasma-enhanced chemical vapor deposition (PECVD), ECR-PEMOCVD is more suitable for the deposition of this kind of thin film [36-38]. In this study, InN thin films on a self-standing diamond substrate were successfully prepared by an electron cyclotron resonance plasma-enhanced metal organic chemical vapor deposition [36,37] system and their properties were also studied. 


\section{Experimental Methods}

InN thin films were produced on a self-standing diamond substrate at various deposition temperatures by ECR-PEMOCVD. Independent CVD thick diamond films were adopted as substrates with thicknesses of $0.5-0.8 \mathrm{~mm}$, which were prepared on Mo substrates by direct current (DC) glow discharge PCVD $[33,34]$. In order to acquire freestanding thick diamond films, the laser stripping was used to remove the Mo substrates. The independent diamond films cannot be adopted as InN deposition substrates because of the rough surfaces, therefore, diamond films with smooth nucleation surfaces were used for the growth surfaces. Firstly, diamond films with nucleation surfaces were mechanically polished to meet the demand of InN film deposition. Secondly, the diamond substrates were immersed in a mixture of 3:1 sulfuric acid and phosphoric acid at room temperature for $24 \mathrm{~h}$, so a thin layer of metal carbide formed by high temperature for a long time was removed. Finally, toluene, acetone, ethanol and deionized water were used sequentially for substrate ultrasonic cleaning, $\mathrm{N}_{2}$ was used for drying, and the substrate was ultimately introduced into the reaction chamber. The substrate was polycrystalline diamond, which is diamond with a (111) and (220) preferential orientation. $\mathrm{H}_{2}$ was discharged through the microwave system. Under the conditions of plasma gas discharge, the self-standing diamond substrate was rinsed at a $60 \mathrm{sccm}$ hydrogen flow rate and a $650 \mathrm{~W}$ microwave power for $0.5 \mathrm{~h}$ at room temperature. Finally, cleaned substrates were ready for the subsequent deposition.

The trimethyl indium (TMIn) and high-purity $\mathrm{N}_{2}$ were adopted as indium and nitrogen sources, respectively. The ionization reaction of $\mathrm{N}_{2}$ was dramatically improved by ECR with $\mathrm{H}_{2}$ as a carrier gas. A semiconductor cold trap was adopted to accurately keep the TMIn temperature at $20 \pm 1{ }^{\circ} \mathrm{C}$. The enhanced effect of ECR collects a large number of activated nitrogen ions on the substrate, which was crucial for the formation of InN films. The lattice mismatch between InN films and diamond substrates should be alleviated effectively, so a buffer layer was required. Buffer layer films were prepared under conditions of a $60 \mathrm{sccm} \mathrm{N}$ flow rate at room temperature, a trimethyl indium (TMIn) $0.3 \mathrm{sccm}$ flow rate and $30 \mathrm{~min}$ of preparation. The growth was continued for $180 \mathrm{~min}$ under the conditions of a microwave power of $650 \mathrm{~W}$ and flow rates of TMIn and $\mathrm{N}_{2}$ of 0.6 and $100 \mathrm{sccm}$, respectively. When the temperature of deposition varied from 200 to $600{ }^{\circ} \mathrm{C}$, the effects of temperatures on the structure and the thin film properties were studied. The temperature was accurately manipulated by a computer-based temperature controller. The thickness of the InN films was up to $350 \mathrm{~nm}$.

The properties of structure and preferential orientation of films were characterized by $\mathrm{X}$-ray diffraction (XRD, D/Max-2400, Cu K $\alpha_{1}: \lambda=0.15406 \mathrm{~nm}$, Rigaku, Tokyo, Japan) and reflection high-energy electron diffraction (RHEED). Film surface morphology was analyzed by scanning electron microscopy (SEM) and atomic force microscopy (AFM). The electrical properties were obtained with a Hall effect measurement system (HL5500, Bio-red, Almada, Portugal) and X-ray photoelectron spectroscopy (XPS).

\section{Results and Discussion}

\subsection{RHEED Measurement of InN Thin Films Prepared at Varying Temperatures}

As shown in Figure 1, RHEED was used to characterize InN thin films prepared at different deposition temperatures. As the temperature increased from 200 to $400{ }^{\circ} \mathrm{C}$, RHEED patterns of InN films gradually changed from continuous rings to broken rings, and the resolution of patterns became higher. However, if the temperature further increased from 400 to $600{ }^{\circ} \mathrm{C}$, the RHEED patterns gradually changed from broken rings back to continuous rings, and the pattern resolution became lower. This indicates that the RHEED results were dramatically influenced by deposition temperature. For the temperature at $400^{\circ} \mathrm{C}$, the prepared films showed high-resolution RHEED patterns of broken rings. Further analysis reveals that only (002) and (004) diffractions appeared from the middle of the patterns. (101) and (103) crystal planes were also clearly observed at other $1^{\circ}$ cations. Prepared InN thin films showed preferential orientation at $400^{\circ} \mathrm{C}$. Their direction of growth was perpendicular to 
the substrate with a preferential orientation of high $c$-axis. Poor crystallization of prepared films was obtained at other temperatures, indicating that the optimal temperature was $400{ }^{\circ} \mathrm{C}$.

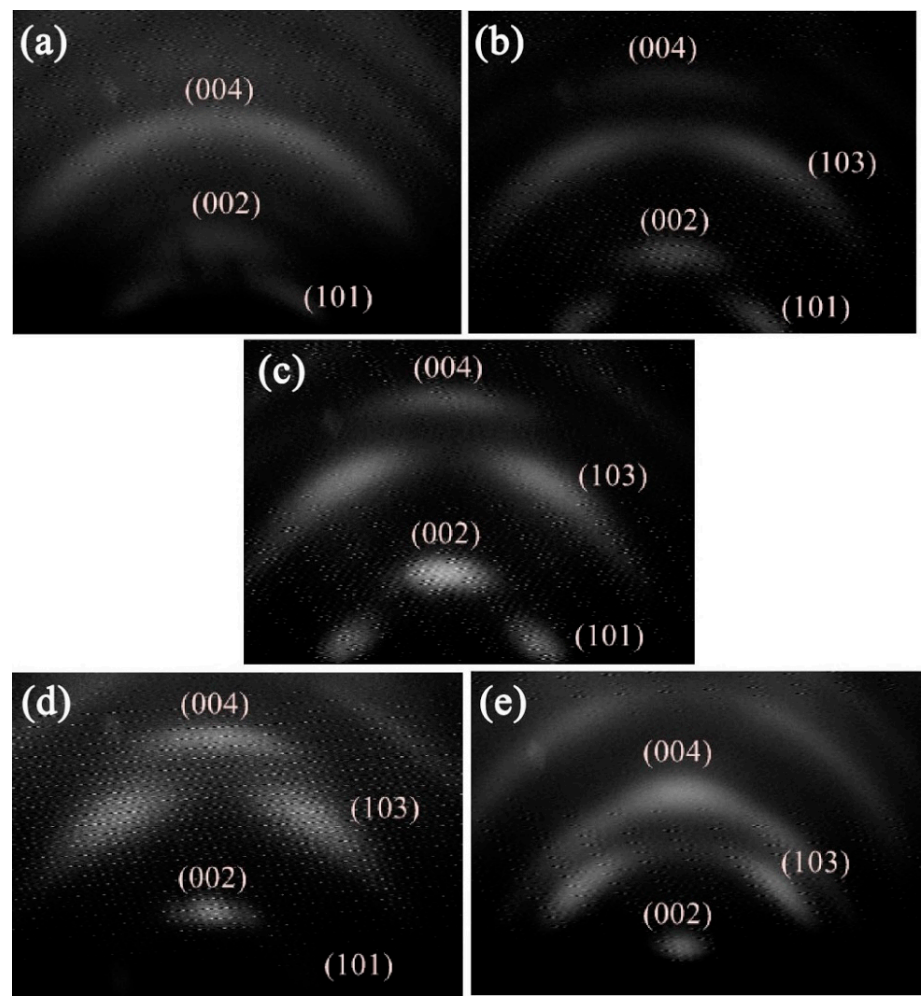

Figure 1. Reflection high-energy electron diffraction (RHEED) patterns of the $\mathrm{InN}$ thin films deposited at (a) $200{ }^{\circ} \mathrm{C}$, (b) $300{ }^{\circ} \mathrm{C}$, (c) $400{ }^{\circ} \mathrm{C}$, (d) $500{ }^{\circ} \mathrm{C}$ and (e) $600{ }^{\circ} \mathrm{C}$.

\subsection{XRD of InN Thin Films Prepared at Varying Temperatures}

The XRD pattern was adopted to characterize the crystallization properties of InN thin films, as shown in Figure 2. The lattice orientations at $43.9^{\circ}$ and $75.4^{\circ}$ are attributed to (111) and (220) diffraction peaks of the substrates. The strongest diffraction peak at $31.3^{\circ}$ is the diffraction peak of the InN films, which is the InN (002) diffraction peak. The InN thin film sample showed a preferred orientation of high c-axis. The as-grown InN films were perpendicular to the self-standing diamond substrates. The effect of varying temperatures on the properties of the films was further studied according to Scherrer's formula:

$$
d=\frac{0.94 \lambda}{B \cdot \cos \theta}
$$

where $d$ is grain size, $\lambda$ is wavelength of $C u K \alpha$ rays $(0.15406 \mathrm{~nm}), \theta$ is Bragg diffraction angle and $B$ is full width at half maximum (FWHM) of the films. The stress of the films was calculated based on the stress formula:

$$
\sigma=\frac{2 c_{13}^{2}-c_{33}\left(c_{11}+c_{12}\right)}{2 c_{13}} \frac{c-c_{0}}{c_{0}}(\mathrm{GPa})
$$

where $c_{11}, c_{12}, c_{13}, c_{33}$ are elastic constants of InN crystal $\left(c_{11}=190 \mathrm{GPa}, c_{33}=182 \mathrm{GPa}, c_{12}=104 \mathrm{GPa}\right.$, $c_{13}=121 \mathrm{GPa}$ ) [35] and $c$ and $c_{0}$ are the $c$-axis lattice constants of InN films and complete crystal. The variation of the stress on films prepared at different temperatures was studied. The $c$-axis diffraction peak positions, FWHM, grain size, tested $c$-axis lattice constants and calculated film stress under varying deposition temperatures are summarized in Table 1. Compared with the reported lattice constant in previous work [38], the lattice parameter is relatively large, and this is probably caused by the film stress. The increase in deposition temperature from 200 to $400{ }^{\circ} \mathrm{C}$ resulted in a gradual reduction in both $c$-axis lattice constant and FWHM and a gradual increase in grain size. However, a further 
increase in temperature from 400 to $600{ }^{\circ} \mathrm{C}$ led to a gradual growth in both $c$-axis lattice constant and FWHM, and a gradual decrease in grain size. Therefore, the films prepared at $400{ }^{\circ} \mathrm{C}$ have a larger grain size and smaller FWHM. Deposited by ECR-PEMOCVD system at lower temperatures, $\mathrm{N}_{2}$ (nitrogen source of the reaction) is not fully dissociated due to less efficient ionization. The dissociated particles could not move to proper positions due to lower migration energy, resulting in a poor crystallization quality of InN films. However, the films at higher temperatures exhibit higher stress, although higher temperatures improve both the ionization reaction efficiency of $\mathrm{N}_{2}$ and migration energy of particles, and the reason can be ascribed to the lattice and thermal mismatch between film and substrate [35]. According to the stress formula, the negative sign means that the value of $c$ is larger than that of $c_{0}$. This indicates that the lattice along the $c$-axis is lengthened and, correspondingly, the films have compression stress inside. This is probably caused by the difference in thermal expansion between InN $\left(4 \times 10^{-6} / \mathrm{K}\right)$ and diamond $\left(3.7 \times 10^{-6} / \mathrm{K}\right)$. Meanwhile, the films are $\mathrm{InN}$ and the substrate is diamond. They have different lattice parameters and thermal expansion. Thus, there exists a mismatch of the lattice parameter and thermal expansion during the heating process. Higher thermal stress generated interfacial defects between the films and the substrates. More importantly, a high temperature may cause the decomposition of InN films and the appearance of metal indium droplets, which would adversely deteriorate the film quality. Therefore, InN films prepared at $400{ }^{\circ} \mathrm{C}$ are of higher crystallinity, in good agreement with the RHEED results.

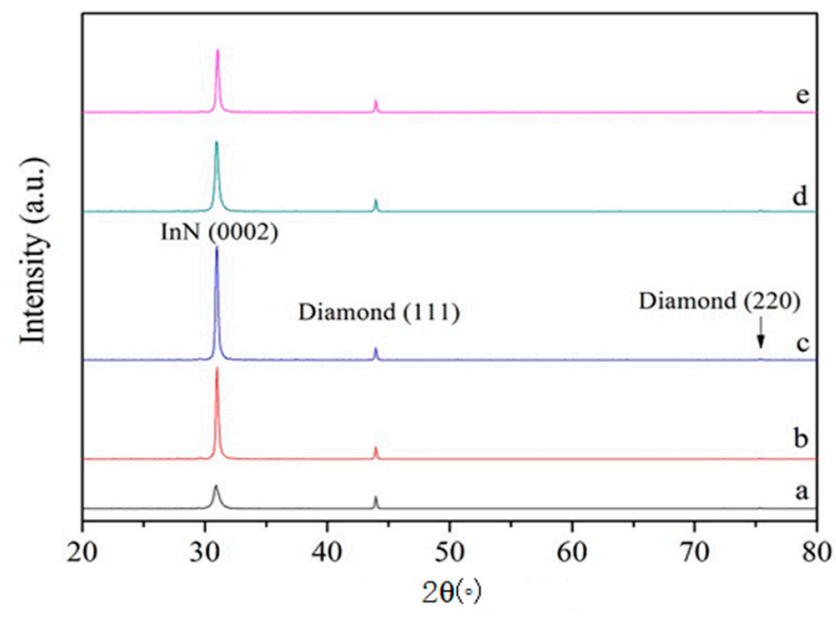

Figure 2. XRD patterns of InN thin films deposited at (a) $200^{\circ} \mathrm{C}$, (b) $300{ }^{\circ} \mathrm{C}$, (c) $400{ }^{\circ} \mathrm{C}$, (d) $500{ }^{\circ} \mathrm{C}$ and (e) $600{ }^{\circ} \mathrm{C}$.

Table 1. InN (0002) diffraction peak position, full width at half maximum (FWHM), grain size, lattice constant and stress.

\begin{tabular}{ccccccc}
\hline Sample & $\begin{array}{c}\text { Temperature } \\
\left({ }^{\circ} \mathbf{C}\right)\end{array}$ & $\mathbf{2 \theta}\left({ }^{\circ}\right)$ & $\begin{array}{c}\text { FWHM } \\
\left({ }^{\circ}\right)\end{array}$ & $\begin{array}{c}\text { Size } \\
(\mathbf{n m})\end{array}$ & $\begin{array}{c}\text { Lattice Constant } c_{\mathbf{0}} \\
(\mathbf{n m})\end{array}$ & $\begin{array}{c}\text { Stress } \boldsymbol{\sigma} \\
\mathbf{( G P a )}\end{array}$ \\
\hline $\mathrm{a}$ & 200 & 31.17 & 0.38 & 26 & 0.5746 & -0.69 \\
$\mathrm{~b}$ & 300 & 31.27 & 0.24 & 31 & 0.5724 & -1.24 \\
$\mathrm{c}$ & 400 & 31.30 & 0.17 & 47 & 0.5708 & -1.96 \\
$\mathrm{~d}$ & 500 & 31.26 & 0.28 & 31 & 0.5737 & -2.52 \\
$\mathrm{e}$ & 600 & 31.19 & 0.31 & 28 & 0.5758 & -3.42 \\
\hline
\end{tabular}

\subsection{SEM Analysis of InN Thin Films Prepared at Varying Temperatures}

Due to the great differences in lattice constants between InN films and self-standing diamond substrates, SEM was used to analyze InN films, as shown in Figure 3. The increase in temperature from 200 to $400{ }^{\circ} \mathrm{C}$ results in higher surface island densities of InN thin films. However, the further increase in temperature from 400 to $600{ }^{\circ} \mathrm{C}$ results in decreased surface island density of thin films, and disordered crystal grain. Figure 3 shows a typical Volmer-Weber growth mode. The corresponding 
process is proposed as follows. Some of the atoms which hit the substrate still have a lot of energy to return to the gas phase, while others are adsorbed on the surface of the substrate. Due to their own energy and the thermal energy gained on the substrate, atoms will drift on the substrate surface and collide with other atoms to form pairs or groups, which eventually form a condensation nucleus. When a certain concentration is reached, no new condensation nuclei are formed. The new adsorbed atoms will drift to the existing condensation nuclei, which leads to the growth of the condensation nuclei and they become small islands, and most of them form micrograins. As the islands grow, adjacent islands contact and combine with each other, so thin films with channels are formed. As the deposition continues, the adsorbed atoms fill empty channels. It is also possible to form new islands, which fill empty channels and, finally, a continuous film is formed. A proper temperature increases the migration energy of surface atoms, facilitating the formation of $\mathrm{InN}$ films. However, the atoms are likely to undergo secondary crystallization due to the excessively high migration energy at a relatively higher temperature.

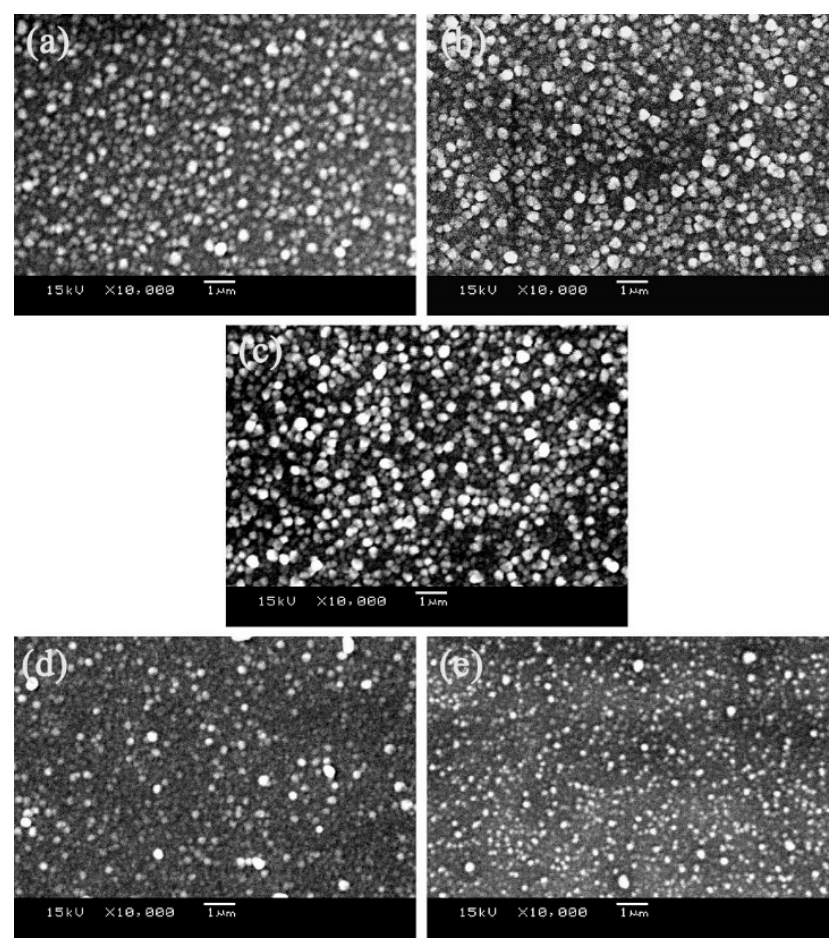

Figure 3. SEM patterns of the InN thin films deposited at (a) $200{ }^{\circ} \mathrm{C}$, (b) $300{ }^{\circ} \mathrm{C}$, (c) $400{ }^{\circ} \mathrm{C}$, (d) $500{ }^{\circ} \mathrm{C}$ and (e) $600{ }^{\circ} \mathrm{C}$.

\subsection{AFM Analysis of InN Thin Films Prepared at Varying Temperatures}

For following up the development of photovoltaic devices based on InN, the flatness of the surface should be controlled to the nanometer level [39-46]. AFM is used to analyze surface morphology of thin films, as shown in Figure 4. The surface roughness of InN films is as low as $10 \mathrm{~nm}$, fully meeting the requirements of surface flatness for a high-power infrared detector. Figure 4 shows a typical Volmer-Weber growth mode. Further analysis shows that surface island density increases as the temperature increases from 200 to $400{ }^{\circ} \mathrm{C}$. However, a further increase in temperature from 400 to $600{ }^{\circ} \mathrm{C}$ results in reduced surface island density and disordered grains. This indicates that the temperature has a great influence on the surface morphology. At $400^{\circ} \mathrm{C}$, the prepared thin films show a smooth surface morphology formed by uniformly dense grains and visible crystal lattice boundaries. Further analysis is based on the root mean square of the surface flatness of the films. When the preparation temperature increases from 200 to $400{ }^{\circ} \mathrm{C}$, the root mean square of the surface roughness decreases from 9.8 to $3.7 \mathrm{~nm}$, and the grain size gradually becomes consistent with the same growth direction. 
When the temperature further increases to $600{ }^{\circ} \mathrm{C}$, the root mean square of the surface roughness increases gradually with more disordered grain growth. Therefore, the $\mathrm{InN}$ film prepared at $400{ }^{\circ} \mathrm{C}$ has optimum morphological characteristics.
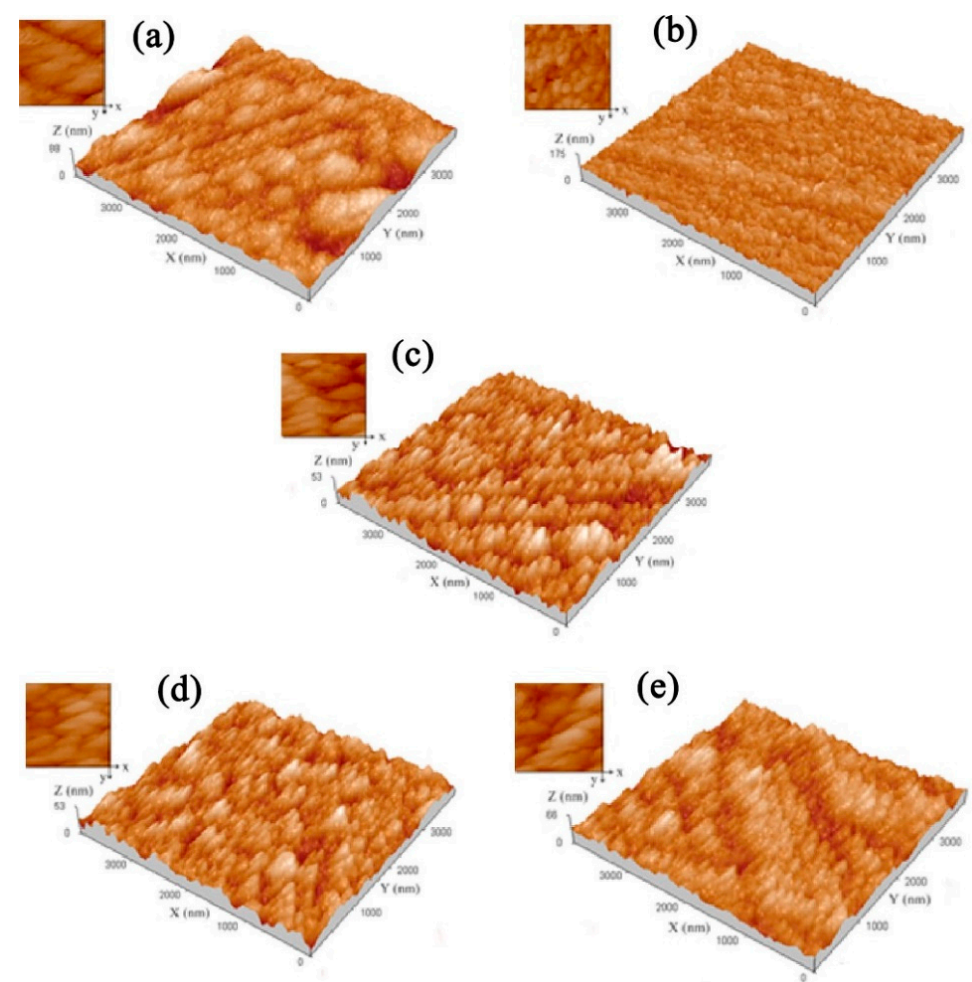

Figure 4. AFM patterns of the InN thin films deposited at (a) $200^{\circ} \mathrm{C},(\mathbf{b}) 300^{\circ} \mathrm{C}$, (c) $400{ }^{\circ} \mathrm{C}$, (d) $500^{\circ} \mathrm{C}$ and (e) $600{ }^{\circ} \mathrm{C}$.

\subsection{Electrical Properties of InN Thin Films Prepared at Varying Temperatures}

The Hall effect system HL5500, manufactured by Accent, is used and the Van der Pauw method is adopted to test the electrical properties of $\mathrm{InN}$ thin films. Electrode contact is used and the magnetic field intensity is $0.338 \mathrm{~T}$. The sample size is $1.2 \mathrm{~cm} \times 1.2 \mathrm{~cm}$, and four probes are located at a vertex angle of $1 \mathrm{~cm} \times 1 \mathrm{~cm}$ in the middle of the sample surface. Because the self-standing diamond substrate is insulated, the electrical property data are all from the InN thin films. As shown in Table 2, all InN thin films exhibit the conductivity of an $n$-type semiconductor, which is supposed to be a unique feature of unintentionally doped InN thin films. This is related to the inherent defects in the thin films [13-15]. The increase in temperature from 200 to $400{ }^{\circ} \mathrm{C}$ leads to a gradual reduction in the carrier concentration but a gradual increase in the mobility of thin films. A further increase in temperature from 400 to $600{ }^{\circ} \mathrm{C}$ results in a gradual increase in the carrier concentration but a gradual decrease in the mobility of thin films. According to previous reports [14-17], higher nitrogen partial pressure leads to the generation of nitrogen vacancies, which is the main reason for the high carrier concentration during the preparation of $\mathrm{InN}$ thin films. InN thin films have been grown on various substrates in previous works, such as sapphire substrates [47], multicrystalline Si substrates [48] and AlN/Si substrates [49]. The mobility in InN films is mainly dominated by grain boundary scattering and defect scattering. Compared with previous reports [26-28], the mobility of InN films in this study is relatively low $\left(0.68 \mathrm{~cm}^{2} /(\mathrm{V} \cdot \mathrm{S})\right)$, but InN films could be prepared at a lower temperature by an ECR-PEMOCVD system. The inert gaseous nitrogen is used as a nitrogen source, increasing the difficulty of preparation. Subsequent work will continue to optimize the experimental parameters for the improvement of mobility. The electrical properties of prepared thin films are consistent with the XRD results. At $400{ }^{\circ} \mathrm{C}$, InN thin films prepared on the self-standing diamond substrate show better electrical properties. 
Table 2. Electrical properties of InN films on diamond substrates deposited at various temperatures.

\begin{tabular}{ccccc}
\hline Sample & $\begin{array}{c}\text { Temperature } \\
\left({ }^{\circ} \mathbf{C}\right)\end{array}$ & $\begin{array}{c}\text { Mobility } \\
\left(\mathbf{c m}^{\mathbf{2}} / \mathbf{( V \cdot S ) )}\right.\end{array}$ & $\begin{array}{c}\text { Carrier Concentration } \\
\left(\mathbf{1 0}^{\mathbf{2 0}} \mathbf{c m}^{-\mathbf{3}} \mathbf{)}\right.\end{array}$ & $\begin{array}{c}\text { Conductivity } \\
\left(\mathbf{S c m}^{\mathbf{- 1}}\right)\end{array}$ \\
\hline $\mathrm{a}$ & 200 & 21.7 & 2.05 & 711.8 \\
$\mathrm{~b}$ & 300 & 32.5 & 1.24 & 644.8 \\
$\mathrm{c}$ & 400 & 48.5 & 0.92 & 713.9 \\
$\mathrm{~d}$ & 500 & 38.4 & 1.15 & 706.6 \\
$\mathrm{e}$ & 600 & 24.2 & 1.78 & 689.2 \\
\hline
\end{tabular}

\subsection{XPS Analysis of InN Thin Films Prepared at $400^{\circ} \mathrm{C}$}

The above results show that the best performance of $\mathrm{InN}$ thin films was obtained when the deposition temperature was at $400{ }^{\circ} \mathrm{C}$ with a self-standing diamond substrate. XPS is used to study the bonding properties of our best films, as shown in Figure 5. Two peaks of 443.3 and $444.5 \mathrm{eV}$ are observed, corresponding to the binding energies of In-In bonds and In-N bonds, respectively. The peak intensity of the In-N bond was significantly higher than that of the In-In bond [36,37]. This demonstrates that there are a large number of $\mathrm{In}-\mathrm{N}$ bonds in our prepared films, indicating the good crystalline quality. The In-In bonds in the films correspond to indium particle formation, which originate from a large number of nitrogen vacancies generated by nitrogen atom volatilization during film preparation.

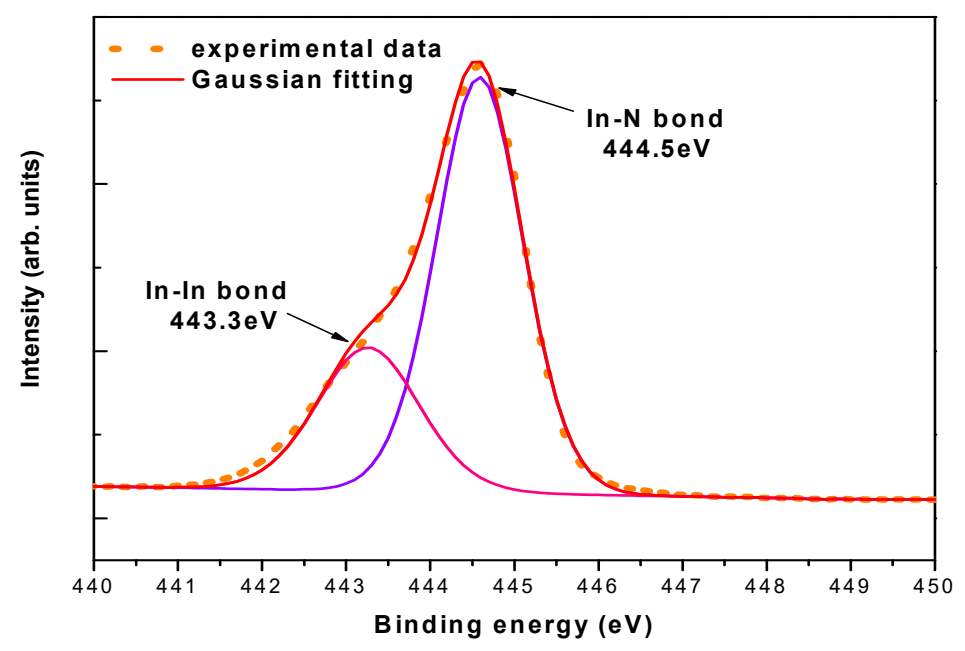

Figure 5. In $3 d_{5 / 2}$ XPS spectra of the InN thin films deposited at $400{ }^{\circ} \mathrm{C}$.

\section{Conclusions}

The temperature of deposition plays a key role in the preferential growth of the (0002) crystal plane of InN films. In this study, an electron cyclotron resonance plasma-enhanced metal organic chemical vapor deposition (ECR-PEMOCVD) system was used to prepare InN thin films on self-standing diamond substrates at different temperatures. The proper temperature is conducive to the optimum quality of InN films. At $400{ }^{\circ} \mathrm{C}$, InN films with highly $c$-axis preferential orientations are obtained. A higher temperature results in a rougher film surface, deteriorating crystallization quality. XPS spectra show the bonding characterization of In-N and In-In in the films. The preferential orientation, optimum surface morphology and electrical properties of InN films can be obtained at a temperature of $400{ }^{\circ} \mathrm{C}$. Given the better heat dissipation performance of self-standing diamond substrates, our achievement will be of special interest for the development of a wide range of InN-based electronic and optoelectronic devices with high power capability and sufficient power durability.

Author Contributions: Data curation, F.Q.; Formal analysis, S.W. and F.Q.; Methodology, D.Z.; Project administration, S.W.; Supervision, Y.B.; Writing-original draft, J.Z.; Writing-review \& editing, J.Z.; All authors have read and agreed to the published version of the manuscript. 
Funding: This work was supported by the National Natural Science Foundation of China under Grant No. 51872036, the fund of Science and Technology Project of Liaoning, China under Grant No. 2019JH8/10100057 and the innovation talent fund of Liaoning Province colleges, China under Grant No. LR2019046.

Conflicts of Interest: The authors declare no conflict of interest.

Data Availability: The data that support the findings of this study are available from the corresponding author upon reasonable request.

\section{References}

1. Spitsyn, B.; Hsu, W.; Gorodetsky, A.; Zalavutdinov, R.; Zakharov, A.; Bouilov, L.; Stoyan, V.; Dvoryankin, V.; Chaplygin, G. AIN heteroepitaxial and oriented films grown on (111), (110) and (100) natural diamond faces. Diam. Relat. Mater. 1998, 7, 356-359. [CrossRef]

2. Van Dreumel, G.; Buijnsters, J.; Bohnen, T.; Ter Meulen, J.; Hageman, P.; Van Enckevort, W.; Vlieg, E. Growth of GaN on nano-crystalline diamond substrates. Diam. Relat. Mater. 2009, 18, 1043-1047. [CrossRef]

3. van Dreumel, G.W.G.; Tinnemans, P.T.; Heuvel, A.A.J.V.D.; Bohnen, T.; Buijnsters, J.G.; ter Meulen, J.J.; van Enckevort, W.J.P.; Hageman, P.R.; Vlieg, E. Realising epitaxial growth of GaN on (001) diamond. J. Appl. Phys. 2011, 110, 013503. [CrossRef]

4. Dussaigne, A.; Malinverni, M.; Martin, D.; Castiglia, A.; Grandjean, N. GaN grown on (111) single crystal diamond substrate by molecular beam epitaxy. J. Cryst. Growth 2009, 311, 4539-4542. [CrossRef]

5. Smith, M.; Cuenca, J.; Field, D.; Fu, Y. GaN-on-diamond technology platform: Bonding-free membrane manufacturing process. AIP Adv. 2020, 10, 035306. [CrossRef]

6. Ahmed, R.; Siddique, A.; Anderson, J.; Gautam, C.; Holtz, M.; Piner, E.L. Integration of GaN and diamond using epitaxial lateral overgrowth. ACS Appl. Mater. Interfaces 2020, 12, 39397-39404. [CrossRef] [PubMed]

7. Vo, D.D.; Vu, T.V.; Nhan, L.C.; Nguyen, C.V.; Phuc, H.V.; Tong, H.D.; Hoat, D.; Hoa, L.T.; Hieu, N.N. Theoretical prediction of electronic and optical properties of haft-hydrogenated InN monolayers. Superlattices Microstruct. 2020, 142, 106519. [CrossRef]

8. Li, H.; Zhang, H.; Wu, H.; Hao, J.; Liu, C. Tree-like structures of InN nanoparticles on agminated anodic aluminum oxide by plasma-assisted reactive evaporation. Appl. Surf. Sci. 2019, 503, 144309. [CrossRef]

9. Ahmad, Z.; Vernon, M.; Cross, G.B.; Deocampo, D.; Kozhanov, A. Supersaturation model for InN PA-MOCVD. arXiv 2003, arXiv:2003.10067.

10. Pham, K.D.; Vu, T.V.; Pham, T.N.; Vo, D.D.; Dang, P.T.; Hoat, D.; Nguyen, C.V.; Phuc, H.V.; Tu, L.T.N.; Van, L.C.; et al. Tuning the electronic, photocatalytic and optical properties of hydrogenated InN monolayer by biaxial strain and electric field. Chem. Phys. 2019, 532, 110677. [CrossRef]

11. Mekys, A.; Jurkevičius, J.; Kadys, A.; Kolenda, M.; Kovalevskij, V.; Tamulaitis, G. Influence of proton irradiation on carrier mobility in InN epitaxial layers. Thin Solid Film. 2019, 692, 137619. [CrossRef]

12. Yamaguchi, T.; Sasaki, T.; Fujikawa, S.; Takahasi, M.; Araki, T.; Onuma, T.; Honda, T.; Nanishi, Y. In situ synchrotron X-ray diffraction reciprocal space mapping measurements in the RF-MBE growth of GaInN on GaN and InN. Crystals 2019, 9, 631. [CrossRef]

13. Cui, H.; Zhang, X.; Li, Y.; Chen, D.; Zhang, Y. First-principles insight into Ni-doped InN monolayer as a noxious gases scavenger. Appl. Surf. Sci. 2019, 494, 859-866. [CrossRef]

14. Adikimenakis, A.; Chatzopoulou, P.; Dimitrakopulos, G.P.; Kehagias, T.; Tsagaraki, K.; Androulidaki, M.; Doundoulakis, G.; Kuzmik, J.; Georgakilas, A. JSS focus issue on recent advances in wide bandgap III-nitride devices and solid state lighting: A tribute to Isamu Akasaki. ECS J. Solid State Sci. Technol. 2020, 9, 015006. [CrossRef]

15. Weiszer, S.; Zeidler, A.; De La Mata, M.; Stutzmann, M. Growth of self-assembled and position-controlled InN nanowires on $\mathrm{Si}$ (111) by molecular beam epitaxy. J. Cryst. Growth 2019, 510, 56-64. [CrossRef]

16. Dobrovolskas, D.; Arakawa, S.; Mouri, S.; Araki, T.; Nanishi, Y.; Mickevičius, J.; Tamulaitis, G. Enhancement of InN luminescence by introduction of graphene interlayer. Nanomaterials 2019, 9, 417. [CrossRef]

17. An, Y.; He, Y.; Wei, H.; Liu, S.; Li, M.; Song, Y.; Qiu, P.; Rehman, A.; Zheng, X.; Peng, M. Metallic indium segregation control of InN thin films grown on $\mathrm{Si}(100)$ by plasma-enhanced atomic layer deposition. Results Phys. 2019, 12, 804-809. [CrossRef]

18. Barick, B.K.; Rodríguez-Fernández, C.; Cantarero, A.; Dhar, S. Structural and electronic properties of InN nanowire network grown by vapor-liquid-solid method. AIP Adv. 2015, 5, 057162. [CrossRef] 
19. Kucera, M.; Adikimenakis, A.; Dobročka, E.; Kúdela, R.; Ťapajna, M.; Laurenčíková, A.; Georgakilas, A.; Kuzmík, J. Structural, electrical, and optical properties of annealed InN films grown on sapphire and silicon substrates. Thin Solid Film. 2019, 672, 114-119. [CrossRef]

20. Miyoshi, M.; Yamanaka, M.; Egawa, T.; Takeuchi, T. Microstructure variation in thick AlInN films grown on c-plane GaN on sapphire by metalorganic chemical vapor deposition. J. Cryst. Growth 2019, 506, 40-44. [CrossRef]

21. Fang, X.; Zheng, F.; Drachenko, O.; Zhou, S.; Zheng, X.; Chen, Z.; Wang, P.; Ge, W.; Shen, B.; Feng, J.; et al. Determination of electron effective mass in InN by cyclotron resonance spectroscopy. Superlattices Microstruct. 2019, 136, 106318. [CrossRef]

22. Liu, J.; Liu, H.; Zhang, A.; Wang, J.; Tang, G.; Zhang, J.; Bai, D. Strain dependent electronic structure and optical properties tuning of InN/PtX $(X=S$, Se) van der waals heterostructures. Vacuum 2019, 168, 108805. [CrossRef]

23. Akasaka, T.; Schied, M.; Kumakura, K. N-face GaN/InN/GaN double heterostructures emitting near-infrared photoluminescence grown by metalorganic vapor phase epitaxy. Appl. Phys. Express 2018, 11, 081001. [CrossRef]

24. Xie, Z.; Zhang, R.; Liu, B.; Li, L.; Liu, C.; Xiu, X.; Zhao, H.; Han, P.; Gu, S.; Shi, Y.; et al. The high mobility InN film grown by MOCVD with GaN buffer layer. J. Cryst. Growth 2007, 298, 409-412. [CrossRef]

25. Zhu, X.; Guo, L.W.; Peng, M.; Ge, B.; Zhang, J.; Ding, G.; Jia, H.; Chen, H.; Zhou, J. Characterization of a-plane InN film grown on r-plane sapphire by MOCVD. J. Cryst. Growth 2008, 310, 3726-3729. [CrossRef]

26. Darakchieva, V.; Lorenz, K.; Barradas, N.P.; Alves, E.; Monemar, B.; Schubert, M.; Franco, N.; Hsiao, C.-L.; Chen, L.-C.; Schaff, W.J.; et al. Hydrogen in InN: A ubiquitous phenomenon in molecular beam epitaxy grown material. Appl. Phys. Lett. 2001, 79, 1489. [CrossRef]

27. De, A.; Tangi, M.; Shivaprasad, S.M. Pre-nitridation induced In incorporation in $\operatorname{In}_{x} \mathrm{Ga}_{1-x} \mathrm{~N}$ nanorods on Si(111) grown by molecular beam epitaxy. J. Appl. Phys. 2015, 118, 025301. [CrossRef]

28. Yamamoto, A.; Tanaka, T.; Koide, K.; Hashimoto, A. Improved electrical properties for metalorganic vapour phase epitaxial InN films. Phys. Status Solidi 2002, 194, 510-514. [CrossRef]

29. Krischok, S.; Yanev, V.; Balykov, O.; Himmerlich, M.; Schaefer, J.; Kosiba, R.; Ecke, G.; Cimalla, I.; Cimalla, V.; Ambacher, O.; et al. Investigations of MBE grown $\mathrm{InN}$ and the influence of sputtering on the surface composition. Surf. Sci. 2004, 849, 566-568. [CrossRef]

30. Wen-Cheng, K.; Chih-Yung, C.; Widi, S. InGaN-based light-emitting diodes grown on various aspect ratios of concave nanopattern sapphire substrate. Appl. Surf. Sci. 2018, 456, 967-972.

31. Roul, B.; Rajpalke, M.K.; Bhat, T.N.; Kumar, M.; Kalghatgi, A.T.; Krupanidhi, S.B. GaAs metal-oxidesemiconductor based nonvolatile memory devices embedded with ZnO quantum dots. J. Cryst. Growth 2012, 354, 208. [CrossRef]

32. Tallaire, A.; Mille, V.; Brinza, O.; Thi, T.N.T.; Brom, J.M.; Loguinov, Y.; Katrusha, A.; Koliadind, A.; Achard, J. Birefringence microscopy of unit dislocations in diamond. Diam. Relat. Mater. 2017, 77, 146. [CrossRef]

33. Gicquel, A.; Hassouni, K.; Silva, F.; Achard, J. Polycrystalline diamond characterisations for high end technologies. Curr. Appl. Phys. 2020, 1, 479. [CrossRef]

34. Schwander, M.; Partes, K. A review of diamond synthesis by CVD processes. Diam. Relat. Mater. 2011, 20, 1287-1301. [CrossRef]

35. Lobaev, M.A.; Gorbachev, A.; Bogdanov, S.; Vikharev, A.; Radishev, D.; Isaev, V.; Chernov, V.; Drozdov, M. Influence of CVD diamond growth conditions on nitrogen incorporation. Diam. Relat. Mater. 2017, 72, 1-6. [CrossRef]

36. Zhi, A.-B.; Qin, F.; Zhang, N.; Bian, J.; Yu, B.; Zhou, Z.-F.; Jiang, X. Low-temperature growth of highly c-oriented InN films on glass substrates with ECR-PEMOCVD. Vacuum 2012, 86, 1102-1106. [CrossRef]

37. Bi, Z.; Ek, M.; Stankevič, T.; Colvin, J.; Hjort, M.; Lindgren, D.; Lenrick, F.; Johansson, J.; Wallenberg, R.; Timm, R.; et al. Self-assembled InN quantum dots on side facets of GaN nanowires. J. Appl. Phys. 2018, 16, 164302. [CrossRef]

38. Zhang, N.; Qin, F.; Bai, Y.; Bian, J.; Li, S.; Pan, L.; Zhi, A.; Liu, X.; Jiang, X. Effect of buffer layer on the structural and morphological properties of GaN films grown with ECR-PEMOCVD. Diam. Relat. Mater. 2012, 21, 88-91. [CrossRef]

39. Sun, J.; Bai, Y.; Yang, T.; Xu, Y.; Wang, X.; Du, G.; Wu, H. Deposition of ZnO films on freestanding CVD thick diamond films. Chin. Phys. Lett. 2006, 23, 1321. 
40. Sun, J.; Bai, Y.-Z.; Yang, T.-P.; Sun, J.-C.; Du, G.-T.; Jiang, X.; Wu, H.-H. Preparation and characteristics of ZnO films on freestanding diamond substrates. Diam. Relat. Mater. 2007, 16, 1597-1601. [CrossRef]

41. Wang, K.; Reeber, R.R. Primary pyroelectric transition temperatures of binary nitrides. Appl. Phys. Lett. 2001, 79, 11.

42. Lee, I.; Yu, C.; Shin, H.; Kim, J.; Lee, Y.; Hur, T.; Kim, H. Growth and nanostructure of InN thin films deposited by reactive magnetron sputtering. Thin Solid Films 2007, 515, 4691. [CrossRef]

43. Takai, O.; Ikuta, K.; Inoue, Y. Some properties of group-III nitride thin films directly grown on non-singlecrystalline substrates by using a molecular beam epitaxy apparatus. Thin Solid Films 1998, 318, 148. [CrossRef]

44. Serrano, J.; Rubio, A.; Hernandez, E.; Munoz, A.; Mujica, A. First-principles investigations on metallic silicon allotropes. Phys. Rev. B. 2000, 62, 16612. [CrossRef]

45. Qian, Z.; Shen, W.; Ogawa, H.; Guo, Q. Capacitance characteristics in InN thin films grown by reactive sputtering on GaAs. Prog. Phys. 2003, 23, 257-283.

46. Novikov, M.V.; Maystrenko, A.L.; Kushch, V.I. Effect of metal catalyst thermal expansion on thermal stability of synthetic diamonds. Comput. Mater. Sci. 2012, 53, 409-415. [CrossRef]

47. Cross, G.B.; Ahmad, Z.; Seidlitz, D.; Vernon, M.; Dietz, N.; Deocampo, D.; Gebregiorgis, D.; Lei, S.; Kozhanov, A. Kinetically stabilized high-temperature InN growth. J. Cryst. Growth 2020, 536, 125574. [CrossRef]

48. Sato, Y.; Saito, S.; Shiraishi, K.; Taniguchi, S.; Izuka, Y.; Saito, T. Vertical alignment of InN- and GaN-based nanopillar crystals grown on a multicrystalline Si substrate. J. Cryst. Growth 2020, 537, 125603. [CrossRef]

49. Chen, W.-C.; Chen, H.-P.; Lin, Y.-W.; Liu, D.-R. Growth of narrow substrate temperature window on the crystalline quality of InN epilayers on AIN/Si(111) substrates using RF-MOMBE. J. Cryst. Growth 2019, 522, 204-209. [CrossRef]

Publisher's Note: MDPI stays neutral with regard to jurisdictional claims in published maps and institutional affiliations. 